\title{
Secondary School Teachers Rationale for giving Formative Feedback
}

\author{
Ilodibe Emeka Chidiebere ${ }^{\mathrm{a}}$, Obiasoanya Kosiso Modest ${ }^{\mathrm{b}, *}$ \\ ailodibec_ec@yahoo.com \\ bladymodestk@gmail.com

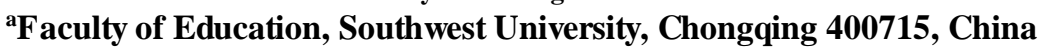 \\ baculty of Education, Southwest University, Chongqing 400715, China
}

\begin{abstract}
Among everyday classroom assessment exercise by teachers, feedback can be seen as connected to the formative function of assessment, helping students learn. Most research on teacher feedback pays more attention to the formative quality of feedback. However, to strengthen researchers' understanding of teacher feedback's nature, we also need to understand more about teachers' rationales for giving their students feedback. This study aimed to explore and conceptualize secondary school teachers' rationales for giving students Feedback. Twenty secondary school teachers was selected from Anambra state, with 4 to 18 years of teaching experience, teaching students aged 11-17 years old (grades 1-6) took part in the study. The study adopted open sampling procedure to recruit teachers. Semi-structured interview approach was used to collect data. The researchers employed a constructivist grounded theory design for the coding and analysis of the transcribed data using simple percentage rating. The study revealed that cognitive objective, students' motivation, academic improvement and teacher-student effectiveness are major reasons for teachers' feedback to students. The study also revealed that the significance of giving feedback is for adjustment and to enhance students' participation while the methods in giving feedback include gifts and awards, punishment, oral and written feedback. The study recommend that both classroom assessment training and classroom management training should be taking seriously in teacher education.
\end{abstract}

\subsection{Introduction}

It has become increasingly conspicuous that the rationale behind secondary school teachers' feedback plays an essential role in the students' lives. Feedback is the return of the output of a process or system to the input, mainly when used to maintain performance or operation. The rationale is the fundamental reasons for a course of action, belief, et cetera. Studies on the real reasons for giving an output process, which in this case is connected to pedagogy, play a significant role in the lives of those concerned. Akpinar M. (2018) believes that feedback promotes teaching and learning and bridges the gap between teacher's pedagogical targets, objectives, and students' overall performance, thereby enhancing the whole process of learning. Feedback promotes and enhances teaching and learning. (Akpinar M., 2018), but not enough study was done to determine or analyze the rationale behind this feedback. This is even more perceptible when it comes to streams of research aiming to find the rationale behind the feedback that secondary school teachers' give. Eriksson E. et al. (2018) believes in assessing classroom activities or learning in which feedback comes to focus. According to the researchers, a look at the teacher's regular classroom assessment shows the role feedback plays, especially as it concerns students' learning processes. They also believe 
that in seeking to understand the nature of teachers' feedback, the rationale behind the feedback needs to be analyzed, thereby giving credence to the present research. When we seek to understand the rationale behind teachers' feedback, the feedback's effectiveness and effect will naturally be exposed. It is the students' output, whether academically, behaviorally, and otherwise, that inspires feedback from the teachers, just like Eriksson E. et al. rightly pointed out that research on teacher's feedback is not restricted to academic performance alone. At the same time, Torrance and Pryor (1998) opined that teachers' daily assessment includes assessing behavioral performances and academic achievement.

According to studies, when teachers give feedback, they mainly provide it in response to the students' academic and emotional output. This makes it essential to understand the students' different kinds of products and the rationale behind the feedback and conclude. It's worth noting that the possible conclusions drawn from studies on the rationale behind primary school teacher's feedback will also reveal, among other things, the teachers' overall integrity and educational experience. This will help determine if the students are getting the training they need to set them for life. Hargreaves (2014) described how studies on teachers' feedback and other factors surrounding the feedback could support students' development as a learner.

Feedback given during formative assessment guides students to measure the gap between their current and desired performance and enhances their learning and satisfaction. To get a positive impact of feedback, it should be active and timely. So the present study tries to introduce feedback in the formative assessment of secondary school students and understand the teacher's rationale for giving feedback. The term 'formative' is open to various interpretations, which means, assessment is carried out frequently carried out and is planned at the same time as teaching. It will be formative in helping the teacher to identify areas where more explanation or practice is needed. The teachers' remark to the students' work may tell the students if they fail or succeed, not progress towards further learning. (Broadfoot et al., 1999, p. 7).

Formative assessment is the type of assessment that monitors student progress, without grading, and uses it to adapt teaching and learning to facilitate students' needs (Black \& William 1998; Boston 2002; Cowie \& Bell 1999; Snowman Beihler 2000). Effective teaching involves imparting information and understanding to students (or providing constructive tasks, environments, and learning) and assessing and evaluating students' knowledge of this information. This helps the next teaching act and can be matched to the present understanding of the students.

Based on studies carried out a few years back, formative feedback is knowledge, word, idea passed on to the learner, which is meant to reshape the learners' thinking or behavior to improve learning. Considering the teacher may also receive student-related information and use it as the basis to change instruction, and focus on the student (or, more generally, the "learner") as the primary recipient of formative feedback herein. The most likely outcome of the research conducted in this area is that good feedback can significantly and efficiently improve learning processes and outcomes if delivered correctly. Those last three words, "if delivered correctly," constitute the crux of this review Shute (, 2008)

Black and William (1998) noted that the feedback information had to be utilized for assessment to be formative. The various treatments that are incorporated in response to the feedback are directed towards active learning.

Importantly, for these differentiated treatments to be selected appropriately, teachers need adequate models of how students will react to and use the feedback. Perrenoud (1998) in his commentary on the Black and William paper, suggested "The Feedback given to students in class is like so many bottles collected and thrown into the sea. No one can be very certain that the message they contain will one day find a receiver".

Black and William (1998a) try to address the influences of feedback, and it is received by reviewing the impact on how feedback is received. Based on their review examined the student perspective, the role of teachers, and some of the systems for the organization of teaching where the formative assessment was a significant component. Teacher's feedback is an interdiscursive process that often sees borrowing from a teacher's discourse, made visible via feedback when they reflectively write about themselves. Lewis and Ketter (2004) clarify that interdiscursivity occurs when there is a "generative reconstruction of a discourse rather than a recapitulation or imitation. It is a process that we associate with learning" For instance, students might use terms, phrases, or descriptions from teacher feedback to revise their writing or reflect on their writing quality. Suppose the students are conscious of the situated meanings 
they adopt to improve or assess their writing. In that case, they are constructing an identity recognized by other members of their discipline.

The information given to students and their teachers about attaining learning goals related to the task or performance is essential for the feedback. These goals can also be wide-ranging and include singing a song, running a race, beating a piece of wood, or judging the success of goal attainment on many dimensions. There is a relationship between feedback and goal-related challenge. Suppose feedback does not lead to reducing the discrepancy between current understandings and goals. In that case, students are most likely to close the gap by overstating their current status or claiming various attributions that minimize effort and engagement.

\subsection{Statement of the Problem}

In recent findings, researchers have written on the impact of feedback on students, how feedback can be enhanced, further feedback focuses, and interventions. Hence, studies focusing on teachers' feedback rationales that allow teachers to discuss their perspective, and understanding on feedback in their own words is limited. The study seeks to explore and conceptualize secondary school teachers' rationale for giving feedback.

\subsection{The objective of the study}

This study's primary purpose is to determine the rationale for secondary school teachers' feedback to students.

Specifically, the study is to;

- Find out the rationale behind the feedback that secondary school teachers give.

- To find out the intentions of the teacher who provide this feedback.

- To further understand the methods, this feedbacks are given to the students.

\subsection{Research Questions}

- What are the rationales behind the feedbacks that secondary school teachers give?

- What are the intentions of the teachers who provide this feedback?

- What are the methods used in providing feedback to the students

\subsection{Significance of the Study}

The study contributes to the literature and as well to teachers and teacher educators by presenting a systematic conceptualization of teachers' rationales for giving students feedback in the classroom, and to serve as a base for other research to be carried out on this topic as upcoming researchers can benefit from this research when conducting theirs.

\section{Review of related literature}

Hargreaves (2014) portrayed how knowledge of teachers' feedback and other factors surrounding the feedback can efficaciously support the students' development as independent learners. His prospect for feedback and rationale shows the significance of this present study. There is a sundry understanding the word "feedback," but for the sake of the present study, the researchers decide to instead go for a comprehensive view, including how Hattie and Timperley (2007) see the word. The study will review the literature on the concept of feedback, formative assessment, and the rationale for teacher's feedback to students.

\subsection{Concept of feedback}

A good number of foreign experts consider feedback to be an essential element of Assessment for Learning (Black, Harrison, Lee, Marshall, \& Wiliam, 2003; Clarke, 2003; Hattie, 2009; Sadler 1989, 1998), with Hattie and Timperley (2007, p. 102) calling it "among the most critical influences on student learning." It can help learners' 
satisfaction and persistence to increase greatly. (Kluger \& DeNisi, 1996), and contribute to students adopting more productive learning strategies (Vollmeyer \& Rheinberg, 2005). According to Lewis (2004), through feedback, teachers become aware of the information about the students' learning progress and evaluate their teaching. Hill (2007) had a strong affinity that 'Feedback plays a significant role in ensuring that learners move around the learning cycle. For example, feedback supports the process of reflection and the deliberation of new or more in-depth theory. Through negotiating, feedback can also help the learner plan effectively and efficiently for the next learning experience' (Multiprofessional Faculty Development, 2018).

A central part of teaching for conceptual understanding is a dialog with students to clarify their existing ideas and help them toward scientifically established ideas (Driver, Asoko, Leach, Mortimer, \& Scott, 1994; Scott, Mortimer, \& Ametller, 2011). This involves providing feedback to students about how their established conceptions relate to scientifically accepted ones and help students revamp their thinking accordingly. Feedback is an integral part of the subsequent assessment, and many educational researchers consider feedback as the most compelling aspect of student learning (Bell, 2007; Hattie \& Timperley, 2007; Shavelson et al., 2008). Type of Feedback, however, is essential, and evidence from various studies shows that some kinds of feedback are more serviceable and operative than others (Black \& Wiliam, 1998; RuizPrimo \& Furtak, 2007). Feedback about the person (usual praise) is the least effective (Black \& Wiliam, 1998; Butler, 1995; Hattie \& Timperley, 2007). The feedback that relates to specific and clear goals and processing of the task (Hattie \& Timperley, 2007; Hodgson \& Pyle, 2010; Sadler, 1989) focuses on students' ideas (Chin, 2006; Coffey et al., 2011; Harlen, 2003), and offers guidance for improvement (Bell \& Cowie, 2001; Black et al., 2003) are beneficial. Teachers, peers or one can provide feedback. (Bell \& Cowie, 2001; Black et al., 2003).

According to Hattie and Timperley (2007, p. 81) defined feedback as "information provided by an agent (for instance, teacher, peer, book, parent, self, experience) regarding aspects of one's performance or understanding," highlighting that feedback legitimately comes from non-teacher sources. Opinion varies about who should provide feedback when examining research about feedback, how and when it is best delivered, what the feedback should contain, and why it should be provided. Feedback is invigorating for the productivity of the knowledge and skill necessary for the students. It also offers essential information about revealing the teacher's and students' performance (Akpinar, 2018). At this junction, feedback is an important factor in creating learning needs. Cohen (1992) defines feedback as a strong and crucial tool in designing learning. With the help of feedback, students, teachers and administration are being provided with developing ideas. Effective feedback depends on the students' idiosyncratic capacity and motivation and the differences of intended learning outcomes. Hattie and Timperley (2007) claim there back reducing the differences between information and understanding, and between the obtained learning results and expected results. Teachers and students can reduce this difference with effective feedback.

\subsection{Who should provide feedback?}

Consequently, teachers have been responsible for giving feedback. Nevertheless, during the last two decades, with the global rise of student-centered activities of educating and Assessment for Learning policies, there is increasing agreement that students are legitimate sources of Feedback (Andrade, 2010; Black, Harrison, Lee, Marshall, \& Wiliam, 2003; Strijbos \& Sluijsman, 2010). Peer- and self-assessment practices encourage students to identify learning objectives and understand the criteria used to judge their work and increase self-regulation (Andrade, 2010). Using students as sources of feedback can potentially mitigate teacher feedback problems related to timeliness and frequency (Andrade, 2010) and perceived psychological risks for students (van Gennip, Segers, \& Tillema, 2010). While teacher feedback is conventionally regarded as more accurate, topping (2010) has suggested that peer and student feedback is no less reliable and valid than teacher feedback. However, students still require training in these practices (Andrade, 2010; Brown, \& Harris, 2012. Gielen, Peeters, Dochy, Onghena, \& Struyven, 2010) and the nature of this training will be influenced, in part, by the classroom teacher's understandings of feedback. The measurement and cooperativeness of feedback from peers and the self wholly depends on interpersonal relationships and psychological issues related to self-disclosure and trust (Cowie, 2009; Peterson \& Irving, 2008; van Gennip et al., 2010), requiring students to take on the complex role of assessor (Topping, 2010). Research has indicated that some students and teachers question the validity and reliability of the feedback received through these practices. (e.g., Harris, Harnett, \& Brown, 2009; Harris \& Brown, 2010; Peterson \& Irving, 2008; 
Ross, 2006), with studies showing that, especially among younger students, peer-feedback cannot be expected to be as accurate as expert Feedback (Gielen et al., 2010). van Gennip et al. (2010) found that while student trust in feedback from peers grew after partaking in peer assessment. It was much more challenging to get students to gain self-assurance in their skills as feedback providers, despite feeling psychologically safer than receiving teacher feedback. Therefore, part of the challenge of implementing such practices is confuting students and other stakeholders that students can be operative assessors of their work.

\subsection{What feedback should contain and why it should be given}

Theoretically and with the scientific experiment based models describe multiple types of feedback content, each with different purposes or outcomes (Askew \& Lodge, 2000; Butler \&Winne, 1995; Hargreaves, 2005; Hattie \& Timperley, 2007; Shute, 2008; Tunstall \& Gipps, 1996). Hattie and Timperley's (2007) review of feedback literature identified four types of feedback, along with factors mediating their effectiveness: Feedback Task (i.e., whether work was correct or incorrect), Feedback Process (i.e., comments about the processes or strategies underpinning the task), Feedback Self-regulation (i.e., reminders to students about strategies students can use to improve their work), and Feedback Self (i.e., non-specific praise and comments about effort). Research indicates self-regulation feedback leads to greater student engagement, energy, and self-efficacy, making it the most potent type (Butler \& Winne, 1995; Hattie \& Timperley, 2007). However, task feedback is the type most frequently provided to students in classrooms (Black \& William, 1998; Harnett, 2007; Hattie \& Timperley, 2007). The role of praise in feedback is particularly contentious. Previous research (e.g., Black \& Wiliam, 1998; Brophy, 1981; Hattie \& Timperley, 2007; Sadler, 1989; Wiliam, 1999) has found that teachers predominantly provide feedback of "low-level" praise or criticism of students' verbal responses and written work. Praise alone is rarely useful because it doesn't have sufficient information to move students forward in their learning (Cowie, 2005; Hattie \& Timperley, 2007; Kluger \& DeNisi, 1996; Shute, 2008). However, Black and Wiliam (2009) have argued that praise can enhance motivation and that judgments (even negative ones) can be viewed as challenges to overcome. There is also evidence that some teachers believe tribute is instrumental in improving student self-esteem (Irving, Harris, \& Peterson, 2011). Making up the mind on when and how to use praise is a complicated issue for teachers as they attempt to promote student well-being alongside academic learning. There are different reasons for providing feedback. Educationally, feedback purposes enhance student learning, moving students along a growth pathway instead of protecting their sense of personal well-being (Boekaerts \& Corno, 2005). There is evidence that some teachers also provide feedback for affective reasons, hoping to encourage student persistence and effort or mediate negative evaluations of student work (Black \& Wiliam, 2009, Irving, Harris, \& Peterson, 2011). However, it is doubtful that this affectivepsychological rationale for feedback effectively improves students' learning outcomes because students need teachers as a source of accurate information about their performance (Pajares \& Graham, 1998). Furthermore, administrators or external stakeholders often require teachers to provide specific feedback (e.g., grades, normreferenced reports), regardless of teachers' beliefs or even best practice research. When examining the effects of feedback, several factors influence its use and mediate its impact on student learning. Foremost is students' ability to interpret and use the feedback and motivation to do so (Sadler, 2010). Additionally, the type, content, timing, complexity, and accuracy of the feedback contribute to its effectiveness. These factors are often under the classroom teacher's control or supervision; consequently, understanding teacher thinking seems critical if AL reforms are implemented.

\subsection{What do teachers believe?}

Few studies have overtly examined teacher beliefs about the nature and target of feedback. Irving, Harris, and Peterson (2011) found that the New Zealand teachers described three types of feedback: spoken or written comments about learning, grades or marks, and spoken or written comments about behavior or effort. The teacher identified four primary purposes for these three types of feedback: ameliorate student s learning process (e.g., providing information about weaknesses in student work and how to correct them), reporting and accuracy (e.g., giving grades, hinting to students about their final results), and encouraging students (e.g., praise, feedback about effort). The fourth purpose was that feedback, in certain situations, usually served no function whatsoever because students did not act on it, making it irrelevant. The final grade given with Narrative Feedback was most strongly related to irrelevance because the teachers believed most students ignored such comments. O'Quin (2009) surveyed 
308 middle school teachers in Louisiana and reported that the endorsement of feedback as a strategy to enhance student learning predicted the practices teachers described in their definitions of feedback. This relationship was much more reliable for teachers of alternative than regular classrooms $(\beta=.43 ; .09$, respectively).

Interestingly, endorsement of the notion that feedback was done because it was required did not have a statistically significant relationship to the kinds of Feedback the Louisiana teachers described in their definitions. This would indicate that teachers' beliefs that feedback improves learning might determine their feedback practices more than external factors. Studies with different teacher populations and in different policy contexts are required.

\subsection{Possible purposes of giving feedback}

The main target of formative feedback is to raise student knowledge, skills, and understanding in some content areas or general skill (e.g., problem-solving). Multiple feedback types may be employed toward the end (e.g., response specific, goal-directed, immediately delivered). In addition to various formats of feedback, there are different functions. Shute (2008). According to Black and Wiliam (1998), feedback can function in two ways: directive and facilitative. Directive feedback helps to remind the student what needs to be fixed or revised. Such feedback tends to be more specific than conducive feedback, which provides comments and suggestions to help guide students in their revision and conceptualization.

There are several cognitive mechanisms by which a learner may use formative feedback. First, it can signal space between a current performance level and some desired performance level or goal. Resolving this space can motivate higher levels of effort (Locke \& Latham, 1990; Song \& Keller, 2001). Formative feedback can downsize uncertainty about how good or bad the student is performing on a task (Ashford, 1986; Ashford, Blatt, \& VandeWalle, 2003). Doubt is an aversive state that motivates strategies to reduce or manage it (Bordia, Hobman, Jones, Gallois, \& Callan, 2004). Because doubt is often not pleasant and may distract attention away from task performance (Kanfer \& Ackerman, 1989), reducing uncertainty may lead to higher motivation and more efficient task strategies.

Second, formative feedback can effectively reduce the cognitive load, especially novice or struggling students (e.g., Paas, Renk1, \& Sweller, 2003; Sweller, Van Merriënboer, \& Paas, 1998). These students can become cognitively overwhelmed during learning due to high-performance demands and thus benefit from supportive feedback designed to reduce the cognitive load. Sweller et al. (1998) supported this claim by showing how work examples' presentation reduces the mental pressure for low-ability students with a complex problem-solving task. Moreno (2004) provided additional support using critical feedback to support novice learners.

Conclusively, inappropriate task strategies, procedural errors, or even misconceptions can be corrected using the pieces of information gotten from feedback (e.g., Ilgen et al., 1979; Mason \& Bruning, 2001; Mory, 2004; Narciss \& Huth, 2004). The corrective function effects appear to be incredibly powerful for more specific feedback.

\subsection{Forms and Methods of giving feedbacks}

Different kinds of feedback are found in literature, as mentioned in the studies carried out by many researchers. Two types of feedback processes were pointed by Ur (2003); first is formative, based on students' writing assignments' instant correction. Another is summative, which beliefs in evaluating students' writing at a particular point in time. According to him, feedback could be univocal (errors to be fully or partially corrected) and equivocal (errors to be indicated not fixed). He separated the idea of assessment from the plan of correction. The former gives general information about learners' performance in writing as good or bad. Simultaneously, the latter provides specific information about learners' performance by illustrating their writing strengths and weaknesses.

The ideas of direct Feedback and indirect Feedback were also discussed by other studies (Ferris, 2003, 2006; Ferris \& Roberts, 2001). Direct feedback is something that explicitly remarks which parts of the student's text should be corrected. Indirect feedback is something that does not provide immediate correction on the students' writing; instead leaves it only just by underlying or listing out the problematic part in coded sign.

In a study carried out by Biber, Nekrasova, and Horn (2011) argued that indirect feedback is practiced more than direct feedback in giving written feedback. According to Westin (2020), feedback can be provided as a single entity, 
i.e., informal feedback on a student's grip of a concept in class or multiple objects, such as formal, formative, and peer feedback stage one of an assessment task. Each has its place in enhancing and maximizing student learning. Informal Feedback: It can occur at any time as it emerges spontaneously in the moment or during an action. Therefore, informal feedback demands students' conformity to encourage, coach, or guide them on management and decision-making for learning effectively. This might take place in the classroom, over the phone, or in an online or virtual classroom. Formal Feedback: Formal Feedback is scheduled into the process. Usually associated with assessment tasks, precise feedback includes marking criteria, competencies, and is recorded for both the student and organization as evidence. Formative Feedback: The sole aim of formative assessment is not just to monitor student learning but also to provide ongoing feedback that instructors can use to improve their teaching and grow significantly in their education. Hence formative feedback is best given early in the course and before summative assessments. Formative feedback helps Students makes excellent improvement and try to avoid repeating the same mistakes.

In some situations, feedback is needed before students can advance or feel the ability to cross the next assessment phase. Summative Feedback: The objective of summative assessment is to compare students learning against the standard through examination at the end of an instructional unit. Summative feedback consists of detailed remarks related to their work features, expressly explains how the mark was gotten from the criteria provided, and additional constructive comments on how the work could be improved. Student peer feedback: With basic instruction and ongoing support, there is no longer a need for teachers to be the only expert within a course. Students can learn to give quality feedback, which is highly valued by peers. Students' learning experiences can be enriched by providing students with regular opportunities to give and receive peer feedback and develop their professional skill sets. Student self-feedback: This is the fundamental objective of feedback for knowledge acquisition. When giving feedback, teachers can provide direction for the students and teach them through explicit modeling and teaching, self-assessment, and goal setting, leading them to become more independent (Sackstein, 2017). To help students reach autonomy, teachers can expressly identify, share, and clarify learning objectives and success criteria; showcase the application of standards using samples; provide guided opportunities for self-feedback.

\subsection{Formative Assessment and feedback}

There are different definitions of formative Assessment. Formative and summative Assessment is often described as being prominent from each other. Black and William (1998) talk in terms of both the formative and summative functions of Assessment. When viewed, Assessment can serve a double purpose - a summative assessment can provide formative feedback. The least restrictive way of seeing formative Assessment is that it is Assessment, which provides the learner with the knowledge that improves their learning and performance. In this sense, an end of the module, if the student receives quality feedback on how they might improve their graded assignment, maybe formative. While a mid-semester, ungraded Assessment may not be formative if all the feedback says is "good work, well done." The focus is clearly on the style and relevance of the feedback and the teacher's ability to provide the learner with comments they can understand and be productive. Bruner (1970, p120). "Learning depends on knowledge of results, when and where the learning can be used for correction." pondering on this statement, we might want to qualify our definition of formative feedback further. It is not enough to provide quality feedback, but we must also offer this in a way that motivates the students to use it. Without supporting students in their use of feedback (be this through module design, training, clear communication of expectations, etc.), feedback given to be formative will only have the potential to be formative. This sense of formative feedback is similar to that of Sadler (1989), who talks in terms of Assessment being formative only if used to close the gap between actual and reference levels (i.e., 'best' expected standards/model answers, etc.) of performance.

All the above citations and views on feedback and rationale show the importance of this present study. There are various understandings of the word "feedback." Still, the researchers choose a rather encompassing view for the present study, including how Hattie and Timperley (2007) see the word.

\section{Research Methodology}

The study was carried out in some chosen government secondary schools in Anambra State, Nigeria. Eight schools were chosen to carry out the research. Three teachers were purposely chosen to be interviewed in each school with 
the basis of years of experience as a teacher and subject, summing up to twenty teachers interviewed in all. Interviews were done, and grounded theory guided the analyses using simple percentage to examine, qualitatively, the teachers' rationales for giving students Feedback. According to Morcom (2014), 'qualitative research methodology strives to understand the participant's world by placing all the researcher's values and assumptions.'

\subsection{Data Collection Method}

Semi-structured one-on-one interviews were conducted to gather information, especially from the teachers via phone calls, video chat, and classroom observation. Considering the distance and the strict measures currently in place to contain the pandemic outbreak, the classroom observation might not be obtainable.

\subsection{Sample size and participant}

A total of 20 teachers were reached to get answers rich in variety. Teachers from different secondary schools were interviewed, and their responses were analyzed to put forward an outcome. Twenty teachers (thirteen women and seven men) with 4 to 18 years of teaching experience, working in Anambra state-owned secondary schools with students aged 11-17 years old (grades 1-6), participated in the study. Purposeful sampling (open sampling) was adopted to recruit the teachers, as it 'seeks to maximize distinctions in teacher's descriptions and experiences using participants from contrasting social environments.' (Hallberg 2006, 143). Following the assertion, we wanted to discover and categorize phenomena common among participants from a broad range of contexts. The participants teach in eight different schools in six educational zone of Anambra state. Some of the schools are located in larger cities and other schools in small rural towns. Some schools have students from the low and mixed socio-economical class of society, some other schools with mixed ethnicity students. In this way, the data were rich in various student populations: socio-economically and ethnically.

\subsection{Data collection}

All three authors conducted interviews. The first twelve teachers from six schools were interviewed initially; four teachers each by the three authors were interviewed individually. As the analysis was ongoing, new questions were raised, which led to additional interviews with four teachers by the first and second authors. These interviews were supplemented by interviews with eight other teachers from four different schools. The researchers conducted the interviews over the phone from PR China. In all, twenty semi-structured interviews were conducted, with an average length of thirty minutes. (An iterative procedure described as theoretical sampling in grounded theory Charmaz 2014). Coding and analysis were carried out parallel with the data collection, resulting in additional interview questions to examine the constructed codes and categories. In the interviews, the teachers were asked the following questions; what is your opinion on classroom assessment? As a teacher, from your perspective, what are the importance of giving feedback to the students in the classroom? What are your possible reasons for providing feedback to the students? What are your targets for this feedback? What methods do you use in giving feedback to the students? Which method is more effective in providing feedback to the students, and does these methods meet feedback needs? The interviewer used probing and follow-up questions (for instance, 'what do you mean?' 'How come?' and 'Tell me more') and took a non-judgmental approach (e.g., Kvale and Brinkmann 2009). The interviews were all recorded and transcribed word to word.

\subsection{Analytical method}

Data analysis was guided using grounded theory methods (Charmaz, 2014; Glaser and Strauss, 1967). We used initial and focused coding, theoretical coding (Glaser 1978), constant comparisons, theoretical sampling, and memo writing to complete the analysis. While adopting grounded theory, the researchers tried to encounter the data with what can be described as an open mind instead of an empty head (Dey 1993). This meant that we tried to put what we already knew aside from the onset, as we pay close attention to data during the analysis. This way, we were able to construct codes that are not only derived from data but were also generated in words that were initially related to the data. In the latter part of the analysis, a constant comparison was made within the interview data and between codes and categories. 
Following the constructivist grounded theory approach, symbolic interactionism was used as an open-ended theoretical perspective combined with curiosity and openness (Charmaz 2014). Accordingly, the definition of the situation was used in terms of how the participants interpret a problem that influences their actions. The main concern addresses what the participants are mainly occupied with (Glaser 1978) about feedback; rationales were regarded as the participants' encourage or motivate logical explanations for acting differently (Alvarado 2003).

After the first set of interviews, a group of focused codes had already been generated, further elaborated, strengthened, and confirmed by the second set of interviews that followed, ensuring saturation and trustworthiness. The different categories of feedback rationales, the teacher's intentions who give the feedback, and the method used in providing these feedback occurred in all participating teachers' descriptions, with slight variations in frequency. Of course, it must be recognized that the method's effectiveness varies based on the subject matter, age, and situation then.

\subsection{Presentation of data analysis}

The researchers concluded that teachers' feedback practices are dependent on what they described as vital needs from the data analysis. The researchers defined vital needs as any need a teacher details as one to be addressed with feedback in the classroom. From every indication, it is assumed that teachers' foremost concern in their feedback practice was to meet student's vital needs in the ongoing classroom condition. For grounded theory, terms used to describe the feedback rationales were modeled from the data as such. Consequently, they are no terms already built within the research field. In this way, the findings address participating teachers' rationales, intentions, and methods used, providing authenticity in a grounded theory approach.

The extracts chosen to illustrate a particular category of teachers' feedback rationales, intentions, and methods used, may arise from a single or just a few teachers. However, they are broad representative of the participants as a group. Albeit all categories were present in every teachers' interview, sometimes a category would be evident. At other times it may be connected to different categories, which made some excerpts more suitable than others for exemplification purposes.

\subsection{Research question 1. Feedback rationale}

\section{The rationales for giving feedback}

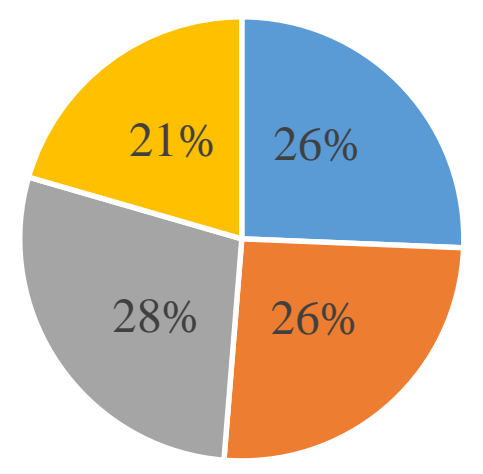

- cognitive objective $\quad$ academic improvement $\quad$ students motivation $\quad$ teacher-student effectiveness

Figure 1. The rationales for giving feedback

Four recurrent patterns of general vital needs for giving feedback to students were constructed and coded representing different kinds of needs; 
Cognitive objective: When it came to the primary concern of students' cognitive need for development, the researchers try to separate it into behavioral and emotional needs. It sometimes had to do with generating order where different rationales for doing so were emphasized in the teachers' statements. At other times, it was all about maintaining order and caring. According to interviewee 5, "The drive is inspired by the behavioral objectives, as a teacher you already have an objective that you want to achieve after the lesson, to make sure that objective is attained."

Students' motivation and Academic improvement: the teacher viewed the students as one in need of support and encouragement to progress academically; this response seems to dominate the interview question "reasons and significance of giving feedback to the students." According to most teachers, "as a teacher, little push is needed to help the students achieve certain academic heights. Feedback has been a means to enhance and motivate students academically. Showing some elements of faith in the students encourages the students and spurs them to perform better.

Teacher-student effectiveness: the rapport between the students and the teacher is of great significance. When the teacher supports the students by giving feedback concerning their academic needs, the motivated students begin to feel free and find comfort with the teacher. The students will be able to tell the teacher their challenges, seeking aid and support to solve these problems, which could be personal problems or certain environmental factors. This way, teacher-student effectiveness is feasible.

\subsection{Research question 2. What are the intentions of the teachers who give this feedback?}

\section{Teachers intentions}

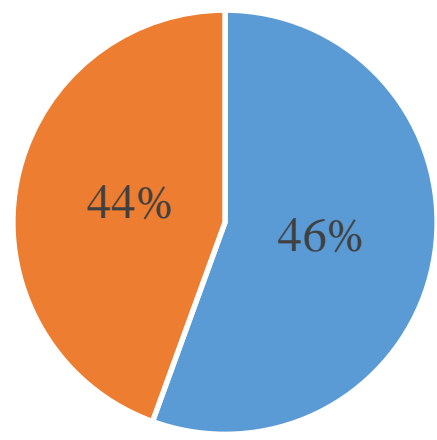

- Adjustment = improved participation

Figure 2, teachers' intentions for giving feedback

The rationale for teachers' feedback and the teachers' intention might look similar but according to the researchers, it has a slight distinguishing meaning. The intention is "what the teacher wants to achieve or obtain when giving feedback to the students while the rationale is simply the reason for giving this feedback to the students. All the teachers stated in their responses that students' feedback is aimed at meeting every students' need except on rare cases where students have a peculiar problem attributed to family issues. Interviewee 5, "While giving the feedback, it can be given generally or individually because student's understanding ability are not equal, and this will help understand the perspective of each student's ability, like knowing which student needs more attention than the other." Some other intentions from the teacher's responses are grouped into two categories mentioned below;

Adjustment: giving feedback helps both students and teachers to adjust and re-strategize teaching methods, whereas the students adjust better academically, the teacher steps up their teaching methods for better understanding. A 
student's low performance could also mean the teacher is lagging in some areas. Effective feedback considers both students and teachers for a better classwork flow.

Improved participation: The teacher's ability to give essential feedback to the students enables them to participate actively in the classroom and their academic lives. Feedback promotes explorative discussions and broader possibilities to ensure focus, thereby creating order and participation.

\subsection{Research question 3. What are the methods used in giving feedback to the students?}

\section{Methods used in giving feedback}

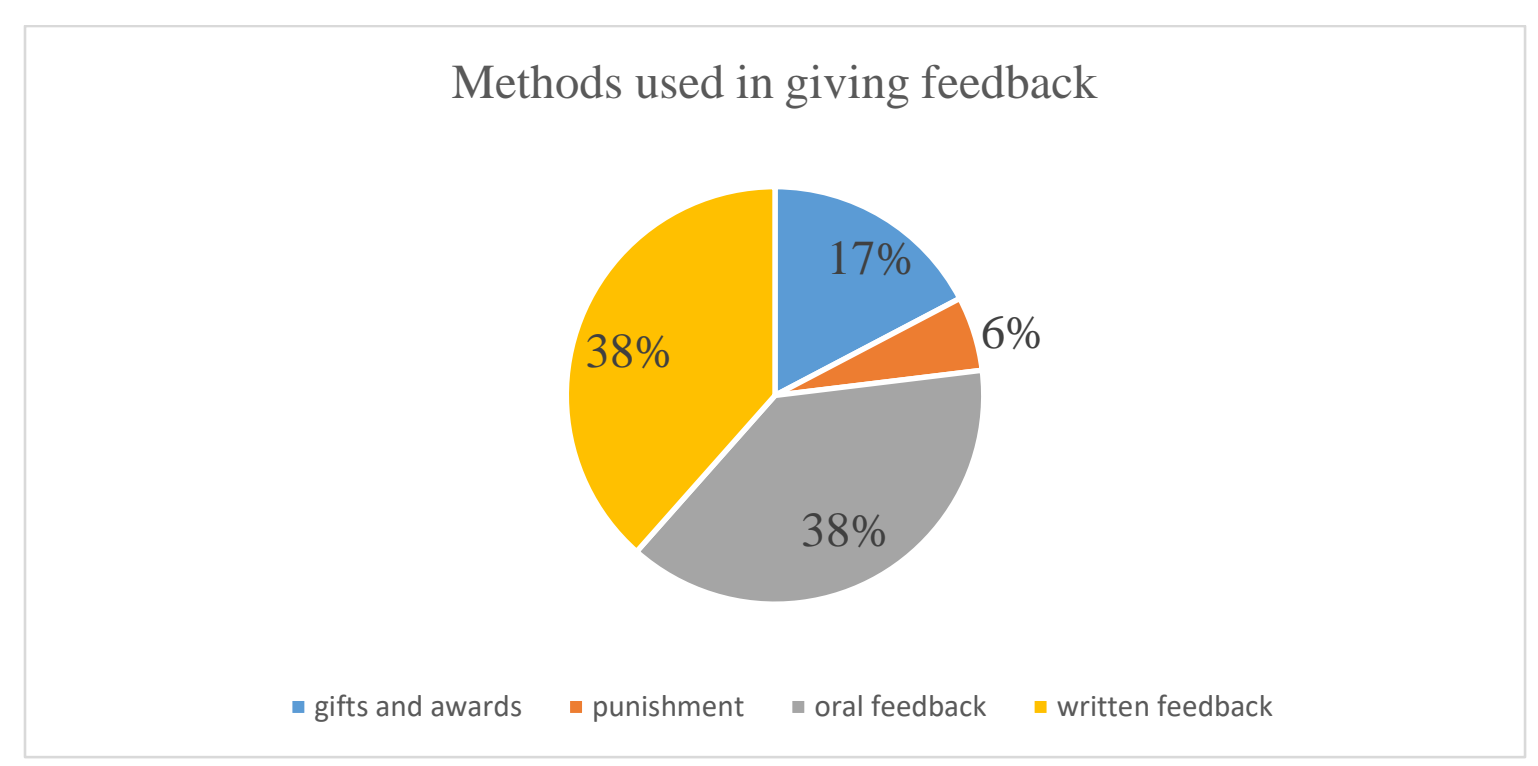

Figure 3, methods used in giving feedback

From the teachers' responses, the researchers try to categorize various mentioned methods used by the teachers to give feedback to the students into the following items mentioned below;

Gifts and awards: The teachers who are deeply concerned with enhancing students' academic and classroom performance often present gifts and prizes to well performed students. According to the teacher, specific tasks will be given to the students, any student who tries their best to efficiently carry out the task is rewarded. The students with better performance or output are encouraged with gifts. This also helps the students with lower performance to do better in the next task.

Punishment: Most teachers seldom use punishment as a method of giving feedback. These students need every reason to participate. Therefore their ability to find a specific approach irrational might make them shy away from the class content. Punishment can be used but only on rare occasions. One of the teachers emphasized slight discipline, like asking the student to stand up or change their sitting position. From the study conducted, few teachers inculcate punishment as a method for giving feedback.

Oral Feedback: Based on the interview conducted, oral feedback happens to be a symbolic and significant method for the teachers. This is mostly associated with giving praise as a strategy to enhance progress. The teachers particularly emphasized encouraging students, especially ones in need of extra learning support. Some students need more encouragement than others. To build confidence in students' learning, it is best to ensure which kind of feedback worked for all student as they all have different learning pace.

Written Feedback: According to teachers on the written aspect, the students are often given a task to reflect on. Students on completion of this task which could be classroom test or examination. The teacher assesses the students by either grading them or writing some encouraging notes on their tasks to enhance motivation and improvement. 


\section{Summary and suggestions for further study}

Based on a systematic analysis of qualitative interview data with secondary school teachers, the recent study offers a framework for surveying, understanding, and communicating the teacher's feedback. It uses some explicit concepts that may be helpfully included in teachers' professional language regarding their teaching practices of classroom assessment and feedback. In line with Tunstall and Gsipps (1996) and Torrance and Pryor (1998), our findings showed that our everyday practices of classroom assessment and management overlapped, which, in turn, details the importance of both classroom assessment training and classroom management training in teacher education. To support professional development, teachers and those involved in teacher development may find it valuable to examine the overlaps and integration between them with reference to the rationales and feedback strategies set out and discussed in our study.

\section{References}

Mehmet Akpinar, 2018. Feedback Strategies Which Social Sciences Teachers Give to Their Students. Universal Journal of Educational Research 6, p. 1317-1327.

Elisabeth Eriksson, Lisa Björklund Boistrup \& Robert Thornberg, 2018. A qualitative study of primary teachers' classroom feedback rationales, Educational Research, 60:2, p. 189-205.

Torrance, H., \& Pryor, J. (2001). Developing Formative Assessment in the Classroom: Using Action Research to Explore and Modify Theory. British Educational Research Journal, 5, p. 615-631.

Hargreaves, Eleanore. 2014. "The Practice of Promoting Primary Pupils' Autonomy: Examples of Teacher Feedback." Educational Research 56, p. 3.

Broadfoot, P. M., Daugherty, R., Gardner, J., Gipps, C. V., Harlen, W., James, M., et al. 1999. Assessment for learning: Beyond the black box. Cambridge, UK: University press.

Black, Paul, and Dylan Wiliam. 2009. "Assessment and Classroom Learning." Assessment in Education 5 (1), p. 7 74.

Shute, V. J. (2008). Focus on formative feedback. Review of Educational Research, 78(1), p. 153-189.

Black, P. J., \& Wiliam, D. 1998. Assessment and classroom learning. Assessment in Education: Principles, Policy, and Practice, 5, p. 7-74.

Philippe Perrenoud, 1998. Formative Evaluation to a Controlled Regulation of Learning Processes. Towards a wider conceptual field, Assessment in Education: Principles, Policy \& Practice, 5:1, p. 85-102.

Lewis, C., \& Ketter, J., 2004. Learning as social interaction: Interdiscursivity in a teacher and researcher study group. In R. Rogers (Ed.). An introduction to critical discourse analysis in education, pp. 117-146. New York: Routledge.

Hattie, John, and Helen Timperley. 2007. "The Power of Feedback." Review of Educational Research 77: 1, p. 81112.

Black, Paul, Christine Harrison, Clare Lee, Bethan Marshall, and Dylan Wiliam. 2003. Assessment for Learning: Putting It into Practice. Maidenhead: Open University Press.

Clarke, S., 2003. Enriching feedback in the primary classroom: Oral and written feedback from teachers and children. London: Hodder \& Stoughton.

Hattie, J. A. C., 2009. Visible learning: A synthesis of over 800 meta-analyses relating to achievement. London: Routledge. 
Sadler, R., 1989. Formative assessment and the design of instructional systems. Instructional Science, 18, p. 119144.

Kluger, A. N., \& DeNisi, A., 1996. The effects of feedback interventions on performance: A historical review, a meta-analysis, and a preliminary feedback intervention theory. Psychological Bulletin, 119(2), p. $254-284$.

Vollmeyer, R., \& Rheinberg, F., 2005. A surprising effect of feedback on learning. Learning and Instruction, 15(6), p. 589-602.

Hill, F., 2007. Feedback to enhance student learning: Facilitating interactive feedback on clinical skills. International Journal of Clinical Skills, 1(1), p. 21-4.

Multiprofessional Faculty Development, 2018. Health education England. August 2020.

Driver, R., Asoko, H., Leach, J., Scott, P., \& Mortimer, E., 1994. Constructing Scientific Knowledge in the Classroom. Educational Researcher, 23(7), p. 5-12.

Scott, P., Mortimer, E., \& Ametller, J., 2011. Pedagogical link-making: A fundamental aspect of teaching and learning scientific conceptual knowledge. Studies in Science Education, 47(1), p. 3-36.

Bell, B., \& Cowie, B., 2001. The characteristics of formative assessment in science education. Science Education, 85(5), p. 536-553.

Shavelson, R. J., Young, D. B., Ayala, C. C., Brandon, P. R., Furtak, E. M., Ruiz-Primo, M. A., Yin, Y., 2008. On the impact of curriculum-embedded formative assessment on learning: A collaboration between curriculum and assessment developers. Applied Measurement in Education, 21, p. 295-314. doi:10.1080/08957340802347647

Ruiz-Primo, M. A., \& Furtak, E. M., 2007. Exploring teachers' informal formative assessment practices and students' understanding of the context of scientific inquiry. Journal of Research in Science Teaching, 44(1), p. 57-84.

Butler, D. L., \&Winne, P. H., 1995. Feedback and self-regulated learning: A theoretical synthesis. Review of Educational Research, 65(3), p. 245-281.

Hodgson, C., \& Pyle, K., 2010. A literature review of assessment for learning in science. Slough: NFER.

Chin, C., 2006. Classroom interaction in science: Teacher questioning and feedback to students' responses. International Journal of Science Education, 28(11), p. 1315-1346.

Coffey, J. E., Hammer, D., Levin, D. M., \& Grant, T., 2011. The missing disciplinary substance of formative assessment. Journal of Research in Science Teaching, 48(10), p. 1109-1136.

Harlen, W., 2003. Enhancing inquiry through formative assessment. San Francisco, CA: Exploratorium, Institute for Inquiry.

Cohen, J., 1992. A power primer. Psychological Bulletin, 112(1), p. 155-159.

Andrade, H. 2010. Students as the definitive source of formative assessment: Academic self-assessment and the selfregulation of learning. In H. L. Andrade \& G. J. Cizek (Eds.), Handbook of Formative Assessment (pp. 90105). New York: Routledge.

Strijbos, J., \& Sluijsmans, D., 2010. Unraveling peer assessment: Methodological, functional, and conceptual developments. Learning and Instruction, 20(4), p. 265-269.

Van Gennip, N. A. E., Segers, M. S. R., \& Tillema, H. H., 2010. Peer assessment as a collaborative learning activity: The role of interpersonal variables and conceptions. Learning \& Instruction, 20(4), p. 280-290. 
Topping, K. J., 2010. Peers as a source of formative feedback. In H. L. Andrade \& G. J. Cizek (Eds.), Handbook of Formative Assessment (pp. 61-74). New York: Routledge.

Brown, G.T., Harris, L., \& Harnett, J., 2012. Teacher beliefs about feedback within an assessment for learning environment: Endorsement of improved learning over student well-being. Teaching and Teacher Education, 28, p. $968-978$.

Gielen, S., Peeters, E., Dochy, F., Onghena, P., \& Struyven, K., 2010. Improving the effectiveness of peer feedback for learning. Learning and Instruction, 20(4), p. 304-315.

Cooper, B. \& Cowie, B., 2009. Collaborative research for assessment for learning. Teaching and teacher education, 26, p. 979-986.

Peterson, E. R., \& Irving, S. E., 2008. Secondary school students' conceptions of assessment and feedback. Learning and Instruction, 18(3), p. 238-250.

Harris, L. R., Harnett, J., \& Brown, G. T. L., 2009. “Drawing” out student conceptions of assessment: Using pupils' pictures to examine their conceptions of assessment. In D. M. McInerney, G. T. L. Brown, \& G. A. D. Liem (Eds.), Student Perspectives on Assessment: What Students can tell us about Assessment for learning (pp. 5383). Charlotte, NC: Information Age Publishing.

Harris, L. R., \& Brown, G. T. L., 2010. Mixing interview and questionnaire methods: Practical problems in aligning data. Practical Assessment, Research \& Evaluation, 15(1). Retrieved from http://pareonline.net/pdf/v15n11.pdf.

Ross, J. A., 2006. The reliability, validity, and utility of self-assessment. Practical Assessment Research \& Evaluation, 11(10). Retrieved from net 20 August 2020. http://pareonline.net/getvn.asp?v=11\&n=10.

Askew, S., \& Lodge, C., 2000. Gifts, ping-pong, and loops - linking feedback and learning. In S. Askew (Ed.), feedback for learning (pp. 1-17). London: Routledge.

Hargreaves, E., 2005. Assessment for learning? Thinking outside the (black) box. Cambridge Journal of Education, $35(2), 213224$.

Pat Tunstall \& Caroline Gsipps, 1996. Teacher Feedback to Young Children in Formative Assessment: a typology, British Educational Research Journal, 22:4, p. 389-404, DOI: 10.1080/0141192960220402

Harnett, P.H., 2007. 'A procedure for assessing parents' capacity for change in child protection cases.' Children and Youth Services Review, p. 29, 9, 1179-1188.

Brophy, J., 1981. Teacher Praise: A Functional Analysis. Review of Educational Research, p. 51(1), 5-32. https://doi.org/10.3102/00346543051001005

Wiliam, D., 1999, May. A template for computer-aided diagnostic analyses of test outcome data. Paper presented at 25th annual conference of the International Association for Educational Assessment held at Bled, Slovenia. London, UK: King's College London School of Education.

Irving, S., Harris, L., \& Peterson, E., 2011. 'One assessment doesn't serve all the purposes' or does it? New Zealand teachers describe assessment and feedback. Asia Pacific Education Review, p. 12(3), 413-426. http://dx.doi.org/10.1007/s12564-011-9145-1

Boekaerts, M., \& Corno, L., 2005. Self-regulation in the classroom: A perspective on assessment and intervention. Applied Psychology: An International Review, p. 54(2), 199-231.

Pajares, M. F., \& Graham, L. (1998). Formalist thinking and language arts instruction: Teachers' and students' beliefs about truth and caring in the teaching conversation. Teaching \& Teacher Education, p. 14(8), 855-870. 
Sadler, D. R. (2010). Beyond feedback: developing student capability in complex appraisal. Assessment \& Evaluation in Higher Education, p. 35(5), 535 - 550.

O'Quin, C. R., 2009. Feedback for students: What do teachers believe? Unpublished doctoral dissertation, The Consortium of Southeastern Louisiana University and the University of Louisiana Lafayette, Hammond, LA.

Locke, E. A., \& Latham, G. P., 1990. A theory of goal setting and task performance. Englewood Cliffs, NJ: Prentice Hall.

Song, S. H., \& Keller, J. M., 2001. Effectiveness of motivationally adaptive computer-assisted instruction on the dynamic aspects of motivation. Educational Technology Research and Development, p. 49(2), 5-22.

Ashford, S. J., 1986. Feedback-seeking in individual adaptation: A resource perspective. Academy of Management Journal, p. 29, 465-487.

Ashford, S. J., Blatt, R., \& VandeWalle, D., 2003. Reflections on the looking glass: A review of research on feedback-seeking behavior in organizations. Journal of Management, p. 29, 773- 799.

Bordia, P., Hobman, E., Jones, E., Gallois, C., \& Callan, V. J., 2004. Uncertainty during organizational change: Types, consequences, and management strategies. Journal of Business and Psychology, p.18 (4), $507-532$.

Kanfer, R., \& Ackerman, P. L., 1989. Motivation and cognitive abilities: An integrative/aptitude-treatment interaction approach to skill acquisition. Journal of Applied Psychology, p. 74(4), 657-690.

Paas, F., Renkl, A., \& Sweller, J. (2003). Cognitive load theory and instructional design: Recent developments. Educational Psychologist, p. 38, 1-4.

Sweller, J., Van Merriënboer, J., \& Paas, F., 1998. Cognitive architecture and instructional design. Educational Psychology Review, p. 10, 251-296.

Moreno, R., 2004. Decreasing cognitive load for novice students: Effects of explanatory versus corrective feedback in discovery-based multimedia. Instructional Science, p. 32, 99-113.

Ilgen, D. R., Fisher, C. D., \& Taylor, M. S., 1979. Consequences of individual feedback on behavior in organizations. Journal of Applied Psychology, p. 64, 349-371.

Mason, B. J., \& Bruning, R., 2001. Providing feedback in computer-based instruction: What the research tells us. Retrieved from http://dwb4.unl.edu/dwb/Research/MB/MasonBruning.html

Mory, E. H., 2004. Feedback research review. In D. Jonassen (Ed.), Handbook of research on educational communications and technology, pp. 745-783. Mahwah, NJ: Erlbaum Associates.

Narciss, S., \& Huth, K., 2004. How to design informative tutoring feedback for multimedia learning. In H. M. Niegemann, D. Leutner, \& R. Brunken (Ed.), Instructional design for multimedia learning, pp. 181-195. Munster, New York: Waxmann.

Ur P., 2003. A Course in English Language Teaching Practice and Theory (10th ed). UK: CUP.

Ferris, D. R., 2003. Response to student writing: Implications for second language students. Mahwah, NJ: Lawrence Erlbaum Associates.

Ferris, D. R. 2006. Does error feedback help student writers? New evidence on the short- and long-term effects of written error correction. In K. Hyland \& F. Hyland (eds.), p. 81-104.

Ferris, D., \& Roberts, B., 2001. Error feedback in L2 writing classes. How explicit does it need to be? Journal of Second Language Writing. 10(3), p. 161-184.

Biber, D., Nekrasova, T., \& Horn, B., 2011. The effectiveness of feedback for 11-English and 12-writing development: a meta-analysis. ets research report series, 2011, p. 99. 
Sackstein, Starr. 2017. Peer feedback in the classroom: Empowering students to be experts. Alexandria, VA. ASCD. Retrieved May 13, 2019, from http://www.ascd.org/publications/books/117020/chapters/The-RationaleforTeaching-Students-to-Provide-Peer-Feedback.aspx.

Bruner J.S., 1970. Some theories on instruction. In Stones E. (Ed.) Readings in Educational Psychology, Methuen, London.

Sadler, R., 1998. Formative assessment: Revisiting the territory. Assessment in Education, 5(1), p. 77-84.

Morcom, Veronica. 2014. "Scaffolding Social and Emotional Learning in an Elementary Classroom Community: A Sociocultural Perspective." International Journal of Educational Research 67, p. 18-29. doi:10.1016/j.ijer.2014.04.002.

Hallberg, Lillemor R.-M., 2006. "The 'Core Category' of Grounded Theory: Making Constant Comparisons." International Journal of Qualitative Studies on Health and Well-Being 1 (3), p. 141-148. doi:10.1080/17482620600858399.

Charmaz, Kathy. 2014. Constructing Grounded Theory. 2nd ed. London: Sage.

Kvale, Steinar, and Svend Brinkmann. 2009. Interviews: Learning the Craft of Qualitative Research Interviewing. London: Sage.

Glaser, Barney. 1978. Theoretical Sensitivity: Advances in the Methodology of Grounded Theory. Mill Valley, CA: Sociological Press.

Dey, Ian. 1993. Qualitative Data Analysis: A User-Friendly Guide for Social Scientists. London: Routledge.

Alvarado, José Luis. 2003. "Teachers' Rationale and Procedures Used during Lesson Script Deviations.” Behavioral Disorders 28 (4), p. 370-385 http://www.jstor.org/stable/23889206.

Tunstall, Pat, and Caroline Gsipps. 1996. "Teacher Feedback to Young Children in Formative Assessment: A Typology.” British Educational Research Journal 22 (4), p. 389-404. doi:10.1080/0141192960220402.

Torrance, Harry, and John Pryor. 1998. Investigating Formative Assessment: Teaching, Learning and Assessment in the Classroom. Buckingham: Open University Press. 